\title{
Microstrain of Human Root Dentin after Chelating Agents Application
}

\author{
Abdillah Imron Nasution
}

\begin{abstract}
Objective: To determine the effect of ethylene diamine tetra acetic acid (EDTA) and RcPrep to microstrain of human root dentin.

Materials and method: Fifteen extracted human premolars were sectioned at the cementoenamel junction using a diamond bur disk. Every group was then sectioned horizontally in the third cervical, third middle and third apical to have total of 45 specimens. Based on the test solutions used, specimens were divided randomly into three groups: (1) the EDTA group: $0.05 \mathrm{ml}$ of $17 \%$ EDTA for 15 minute $(n=15),(2)$ the RcPrep group, $0.05 \mathrm{ml}$ of $15 \%$ EDTA-urea peroxide-carbowax for 15 minutes $(n=15)$, and (3) the control group, $1 \mathrm{ml}$ of $0.9 \%$ saline for 15 minutes $(n=15)$. All specimens were prepared for the determination of microstrain of root dentin using X-ray diffraction (XRD) analysis. The microstrain of root dentin calculated using the equation $\eta=B_{r} \cos \theta / \sin \theta$ then statistically analyzed using regression test.
\end{abstract}

Result: Analysis of regression between control and treatment groups were significant $(p<0.05)$. The microstrain was significantly greater with $17 \%$ EDTA when compared with $15 \%$ RcPrep. In addition, based on XRD result, all specimens showed same patterns as apatite groups. The pattern of RcPrep group showed better material than EDTA group.

Conclusion: EDTA and RcPrep can contribute to improvements of microstrain of root dentin. In comparing these properties, the RcPrep showed lower effect than EDTA.

Keywords: Apatite, Chelating agent, EDTA, Human root dentin, RcPrep,

How to cite this article: Nasution Al. Microstrain of Human Root Dentin after Chelating Agents Application. Int J Experiment Dent Sci 2016;5(1):11-15.

Source of support: Nil

Conflict of interest: None

\section{INTRODUCTION}

Chelating agent is solutions consisting of a synthetic amino acid which assist widening root canal properly because it has ability to softening hard tissue with low negative effect on the periapical tissues. The most common chelating agents used include ethylene diamine

\footnotetext{
Faculty

Department of Oral Biology, Faculty of Dentistry, Syiah Kuala University, Aceh, Indonesia

Corresponding Author: Abdillah Imron Nasution, Faculty Department of Oral Biology, Faculty of Dentistry, Syiah Kuala University, Aceh, Indonesia, Phone: 06206517555183, e-mail: nasution@unsyiah.ac.id
}

tetra acetic acid (EDTA) and ethylene diamine tetra acetic acid + urea peroxide and carbowax (RcPrep). ${ }^{1}$

The application of chelating agent into root canal were known improving the dimensions of human root dentin canal, in other word chelating agents have an ability to decompose the body wall of human root dentin canal. Previous study stated chelating agents change human root dentin hardness along with the length of application of the chelating agent. ${ }^{2,3}$ These events indicate occurrence of increasing of micro strain in human root dentin. The increasing of micro strain identified capable to increasing fracture-risk on human root dentin to lead improving hypersensitivity during mastication and in worst condition might tooth detached. Most serious cases of fracture should be treating by endodontic surgery. One of most famous treatment by endodontic approach is root resection. ${ }^{4}$

Information about microstrain changes in human root dentin after application of chelating agent still limited. Meanwhile, this initial information also needed to determine the factors of microstrain which caused by noninstrumentation of human root dentin formation. ${ }^{5,6}$ Therefore, it is necessary to investigate the differences microstrain of human root dentin after chelating agents application.

\section{MATERIALS AND METHODS}

This laboratory experimental conducted in Department of Physics, Faculty of Nature and Mathematics Science, Syiah Kuala University in January 2013. Fifteen extracted human premolars were sectioned at the cementoenamel junction using a diamond bur disk. Every group was then sectioned horizontally in $1 / 3$ cervical, $1 / 3$ middle, and $1 / 3$ apical to have total of 45 specimens. Based on the test solutions used, specimens were divided randomly into three groups: (1) the EDTA group: $0.05 \mathrm{ml}$ of 17\% EDTA for 15 minutes $(\mathrm{n}=15)$, (2) the RcPrep group, $0.05 \mathrm{ml}$ of $15 \%$ EDTA-urea peroxide-carbowax for 15 minutes $(n=15)$, and (3) the control group, $1 \mathrm{ml}$ of $0.9 \%$ saline for 15 minutes $(n=15)$.

All specimens were prepared for the determination of microstrain of root dentin using X-ray diffraction (XRD) analysis. Grain size calculated using equation:

$$
\mathrm{D}=\frac{\mathrm{K} \lambda \mathrm{Rad}}{\beta_{\mathrm{r} \cos \theta}}
$$

Where $\mathrm{D}=$ Grain size, $\mathrm{K}=$ shape factor constant (0.9), $\lambda=$ wavelength of the X-ray (1.5405600), $\cos \theta=$ cosine of 
half the $2 \theta$ angle, and $\beta r=$ broadening of diffraction line measured at half its maximum intensity (radians).

The microstrain of root dentin calculated using equation:

$$
\eta=\frac{B_{r \cos \theta}}{\sin \theta}
$$

where $\eta=$ microstrain; $B_{r}=$ full width at half maximum in radian; $\theta=$ diffraction angle. Furthermore, Microstrain value statically analyzed using regression test with each variabel (EDTA and RcPrep).

\section{RESULTS}

X-ray diffraction patterns of the precipitates homogeneously are shown in (Fig. 1). All patterns were typically apatitic and amorf crystallized, although some peaks of homogenous apatites were irregular curves. Generally, all specimens showed similar patterns with the main character looks at the highest intensity in $2 \theta=31^{\circ}-32^{\circ}$. Crystal phase of control showed as $\mathrm{Ca}-\mathrm{Cl}$, EDTA group showed as $\mathrm{CaOH}$, and $\mathrm{RcPrep}$ group showed as fluorapatite. General similar pattern of each group as demonstrate in Graph 1.

The XRD pattern of EDTA confirmed as larger crystal than both control and RcPrep group. Whereas, XRD pattern of RcPrep group confirmed as larger crystal than Control group. Data normality test using Shapiro Wilk using Microsoft Excel Analyze-it version 3.90.5 revealed data are normal $(p>0.05)$. The average value of grain size calculated using the Scherrer equation indicates all treatment groups have larger grain size than control. The largest of grain size crystals founded in EDTA group. Grain size of each group as demonstrate in Table 1.

The Microstrain of Control group showed as lower value than all treatment groups. While, microstrain value of EDTA group showed as a biggest value than Control and RcPrep. The average value of microstrain indicates all treatment groups larger than control. The microstrain values of each group as demonstrate in Table 2.

Regression analysis of between control and treatment groups were significant $(\mathrm{p}<0.05)$. The microstrain was significantly greater in 17\% EDTA when compared to $15 \%$ RcPrep. The relationships between EDTA application effect to control in the category of low and positive relation $\left(R^{2}=0.37\right)$. Regression analysis between microstrain of control and RcPrep also confirmed low and positive relation $\left(R^{(2)}=0.37\right)$. Regression of each microstrain demonstrate on Table 3.

\section{DISCUSSION}

The apatite group is a group of similar isomorphous hexagonal phosphate minerals members were traditionally known as fluorapatite, chlorapatite, and hydroxylapatite. ${ }^{78}$ It is well-established by XRD analysis that the mineral constituent of human root dentin is essentially chlorapatite, and that chlorapatite has a structure differing only in small details from that of the wellcrystallized mineral hydroxyl-apatite and fluor-apatite. ${ }^{9}$ The same pattern as displayed in $2 \theta$ with high intensity which indicate all specimens is same groups in apatite crystal. Each HA crystal is arranged by cell unit in lattice arrangement of $\mathrm{Ca}$ and $\mathrm{P}$, and also the lattice arrangement of $\mathrm{O}$ and $\mathrm{H}^{7}$ Moreover, we suggest chlorapatite is the main structure of human root dentin. The main difference, and in fact the only fully established one, between the two structures is that the hydroxy-apatite has a slightly larger unit cell than fluorapatite or chlorapatite. Similar with this result, Elliot was stated that apatites have the general formula, $\mathrm{Ca}_{10}\left(\mathrm{PO}_{4}\right)_{6} \mathrm{X}_{2}$ where $\mathrm{X}$ is typically $\mathrm{F}$ (Fluorapatite, FAp), $\mathrm{OH}$ (Hydroxyapatite, OHAp), or $\mathrm{Cl}$ (Chlorapatite, ClAp) ${ }^{7}$

As a displayed on result, the pattern of all specimen displayed irregular curve and amorphous phases. Dentin is one of the hard tissues in human body. This hard tissue formed by apatite crystal. It differs with enamel which has more percentage of inorganic. Dentin arranged by composition between inorganic and organic is $70 \%$, organic $20 \%$, and water $10 \%$, whereas enamel is the hardest tissue in the human body and consists of approximately $96 \%$ inorganic minerals, $1 \%$ organic materials, and 3\% water. ${ }^{10,11}$ Although both tissues are comprised of a calcium apatite mineral phase and a protein component, they differ to overall structure
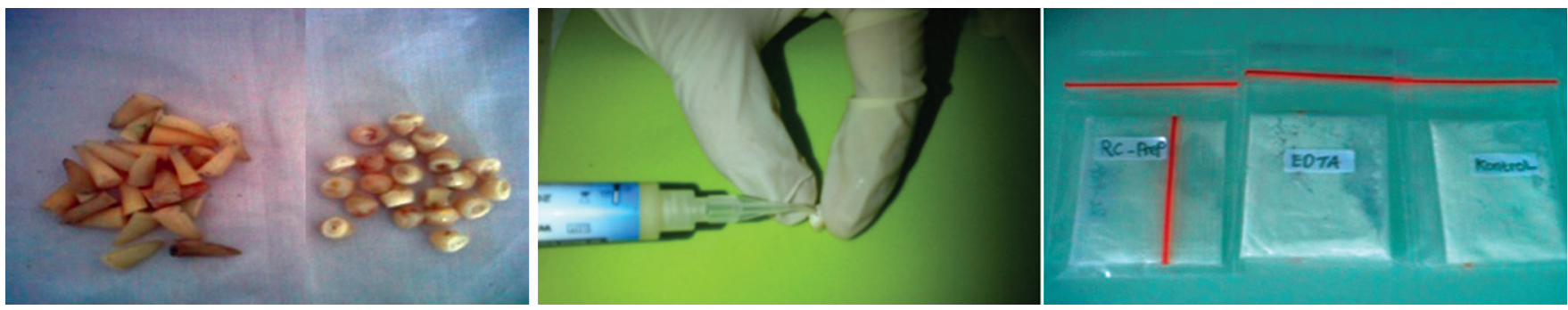

Fig. 1: Preparation of specimens 

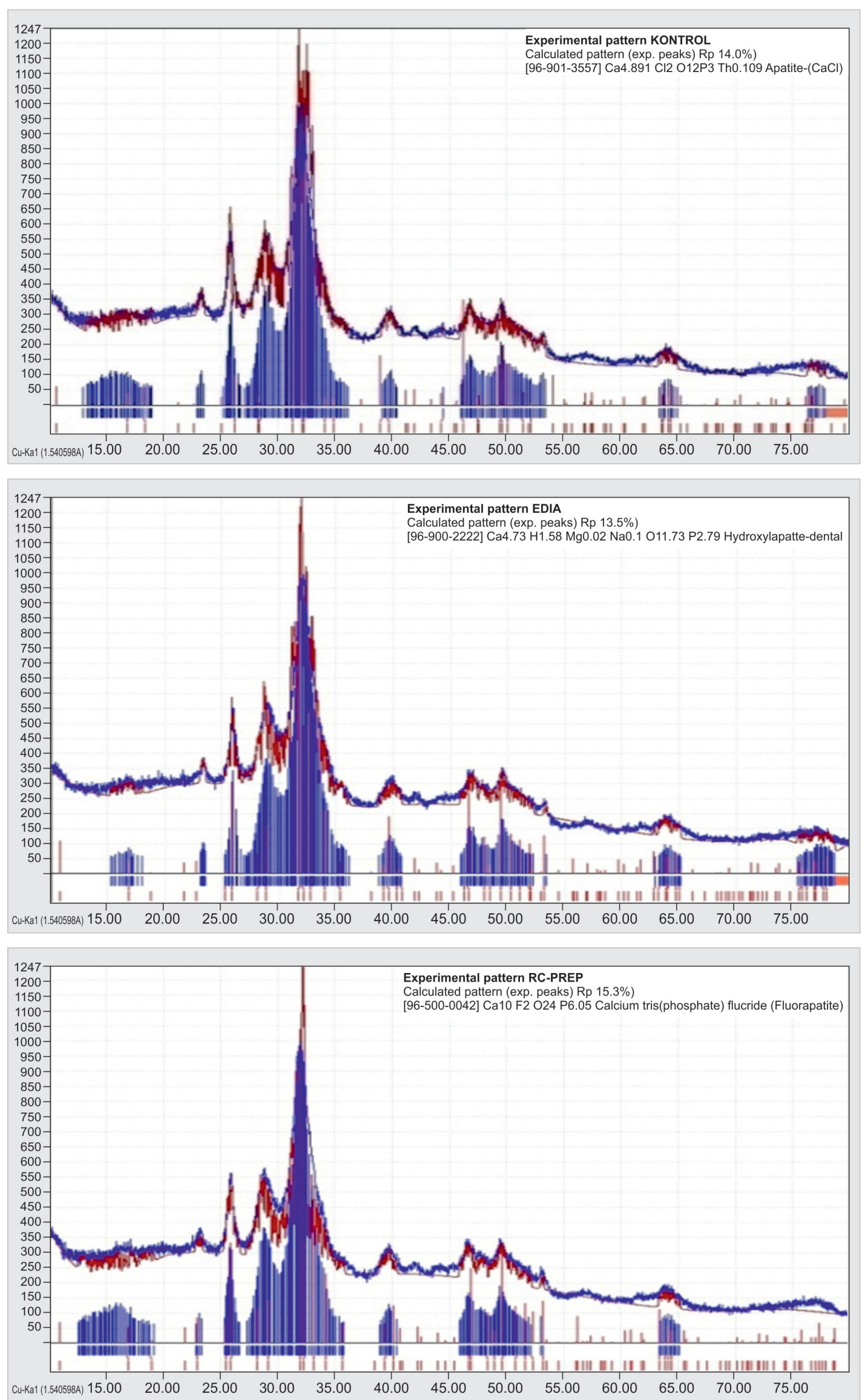

Graph 1: All specimens showed similar patterns with the main character looks at the highest intensity in $2 \theta=31^{\circ}-32^{\circ}$. X-ray diffraction pattern of RcPrep group confirmed as better crystal than both control and EDTA group. Whereas, XRD pattern of EDTA group confirmed as better crystal than control group. X-ray diffraction data have confirmed by Match Crystal 
Table 1: Grain size of each specimen

\begin{tabular}{lll}
\hline & Grain size \\
\hline Control $(\mathrm{nm})$ & EDTA $(\mathrm{nm})$ & RcPrep $(\mathrm{nm})$ \\
\hline 8.2 & 8.9 & 8.8 \\
\hline
\end{tabular}

Table 2: Microstrain of each specimen

\begin{tabular}{lll}
\hline & Microstrain & \\
\hline Control & EDTA & RcPrep \\
\hline 0.895698047 & 0.979657791 & 0.902449062 \\
\hline
\end{tabular}

Table 3: Regression of microstrain

\begin{tabular}{lll}
\hline & $\begin{array}{l}\text { Regression } \\
\text { statistics EDTA } \\
\text { vs control }\end{array}$ & $\begin{array}{l}\text { Regression } \\
\text { statistics RcPrep } \\
\text { vs control }\end{array}$ \\
\hline $\mathrm{R}^{2}$ & 0.37 & 0.38 \\
Coefficient value $\left(\mathrm{F}_{\text {hit }}\right)$ & 10.12 & 10.32 \\
Relationship $\left(\mathrm{T}_{\text {hit }}\right)$ & 3.18 & 3.21 \\
\hline
\end{tabular}

Note: Relationship is significant if $t_{\text {hit }}>t_{\text {table }}$ and relationship is significant if $\mathrm{F}_{\text {hit }}>T_{\text {able }}$

include crystal size and shape, the nature of the proteins present, and the relative proportions of mineral and protein components. Differences in structural organization and composition give rise to mineralized tissues with different properties that are well-suited for their intended biological purpose. ${ }^{12,13}$ Similar with this statement, our result has found the grain size of these hexagonal-member apatites with the formula $\mathrm{Ca}_{5}\left(\mathrm{PO}_{4}\right)_{3}$ $\mathrm{X}(\mathrm{X}: \mathrm{Cl}, \mathrm{OH}, \mathrm{F})$ as found in this experiment: $\mathrm{D}(\mathrm{nm})=8.2$; 8.9; 8.8 for chlorapatite; hydroxylapatite, and fluorapatite. Result has suggest, chlorapatite is main structure of human root dentin, application of both chelating agents EDTA and RcPrep into root canal will change size, structure and microstrain of crystal human root dentin. As we know, apatite crystal is $\mathrm{Ca}_{5}\left(\mathrm{PO}_{4}\right)_{3}(\mathrm{X})$ which $\mathrm{X}$ is able to substitute by other element. This substitution changes of lattice arrangement of cell unit which improving grain size of apatite. The apatite lattice is very tolerant of substitutions, vacancies and solid solutions, e.g., $X$ can be replaced by other elements. ${ }^{14}$ Thus, every cell units of apatite suggested ion Ca position on hexagonal corner to formed calcium column. Ca position is perpendicular to c-axis. Ca position is also on cell central canal which formed Ca triangles. Spaces between Ca columns were placed by two ions $\mathrm{PO}_{4}$ on the hexagonal side. The $\mathrm{F}$ ion position is higher than $\mathrm{OH}$ position on c-axis. ${ }^{13}$ The XRD data of human root dentin which applied to RcPrep have slimmer peak than other group. This found suggest human root dentin which applied to RcPrep have better crystallinity. Calderyn, ${ }^{10}$ was reported that $\mathrm{OH}$ position on $\mathrm{c}$-axis between $1 / 4-$, while ion $\mathrm{F}$ position is $1 / 4$ above the Ca triangle.
Application of RcPrep may cause a remineralization in dentin crystals by $\mathrm{F}$ ion and affect crystal more strength than EDTA application.

The main difference, and in fact the only fully established one, between the two structures is that the hydroxyapatite has a slightly larger unit cell than that of the fluorapatite. These confirm as human root dentin which applied to RcPrep achieved dimensions close to enamel, whereas has better crystallinity than dentin. Previous study also stated 20 of $85 \%$ organic of dentin is arranged by collagen. ${ }^{9,10}$ This organic as confirm in XRD diffractogram displayed as graph or curve pattern is more amorf than enamel. This fact also confirm every mineral have specific diffractogram. Otherwise, EDTA known has the function to clean the root canal as well as bleaching agent which commonly used in dentistry but EDTA proved reducing mineral content of human root dentin. Application of EDTA may cause a reduction in the calcium crystals and increasing percentage of microstrain. These results are consistent with Calt and Serper which states, chelating agents have ability to demineralized human hard tissue. ${ }^{13}$

The increasing of microstrain which imply by EDTA which properly known have capability to dissolving calcium which is found in the building blocks of dentin. Calcium pulled out from crystal arrangement consequently affects crystal structure. Microstain that occurs in dentin due to changes in the structure or position of atoms will influencing root dentin resistance to accepting mechanical forces. ${ }^{14}$ A large grain size of crystal in dissolving dentin and microstrain value, automatically increasing of susceptibility of dentin to fracture. Conversely, both grain size and microstrain of fluorapatite as element which resistance to acid will constant to withstand the mechanical forces.

The results of this study indicate that the application of EDTA is increasing of susceptibility of human root dentin to fracture. Similar with this statement, analyzed data between microstrain controls when compare to EDTA and RcPrep, statistically showed significant effect and positive relationships. In other word, the increasing in microstrain is affected by both chelating agents application. In line with the results, analysis by regression confirms the relationship of chelating agent to improving fracture-risk is positive and weak. It indicates chelating agent application both EDTA and RcPrep predicted have $37-38 \%$ factor which able to increasing of fracture-risk of human root dentin. Concentration and exposure time of chelating agent may lead to main factor to increasing fracture-risk of human root dentin. 
In addition, chelating agent application into root canal will change structure and improving of microstrain. Compilation of microstrain between treatment groups to chlorapatite as control showed application EDTA increasing microstrain on crystal up to $9 \%$ while application of RcPrep only 1\%. Nakano, stated that the crystallinity is strongly influenced by the crystal size and micro strain. ${ }^{12}$ Microstrain obtained from the small size of microstructures on a fluorapatite root dentin was lower up to $1 \%$ while has larger grain size compared to normal (Graph 1). Based on this result, application of RcPrep into human root dentin is better than EDTA in relation to decreasing of dentin fracture.

\section{CONCLUSION}

- Chelating agent application into root canal is either change structure or improving microstrain of apatite crystal.

- Concentration and exposure time of chelating agent may lead as main factor increasing fracture-risk of human root dentin.

- Application of RcPrep into human root dentin is better than EDTA in relation to decreasing of dentin fracture.

- EDTA has ability increasing microstrain of apatite crystal upper than RcPrep.

Dentistry is varying with induction of modern science to practice dentistry. ${ }^{15}$

\section{REFERENCES}

1. Ingle JI, Bakland LK. Endodontics. 5th ed. Canada: BC DeckerInc; 2002. p. 20-96.
2. De-Deus G, Paciornik S, Mauricio MHP. Evaluation of the effect of EDTA, EDTAC and citric acid on the microhardness of root dentinee. Int Endod J 2006;39:401-407.

3. Suminta, Supandi, Evvy K, Sakuma T. Preparation and Characterization of $\lambda$-AgI IN Superionic Composite Glasses (AgI)X(AgPO3)1-X. Indonesian J Mater Sci 2007 Oct;9(1): 72-75.

4. Walton RE, Torabinejad M. Endodonti: The Principal and Practice. 2th ed. Jakarta: EGC 1998. p. 206-246.

5. Goldberq F, Abramovich A, Aires B. Analysis of the effect on the dentineal walls of the of EDTAC root canal. J Endod 1917;3(3):19-24.

6. Eldeniz AU, Erdemir A, Belli S. Effect of EDTA and citric acid solutions on the microhardness and the roughness of human root canal dentine. J Endod 2005;31(2):74-80.

7. Williams RAD, Elliot JC. Basic and Applied Dental Biochemistry. 2nd ed. London, New York: Churchill Livingstone; 1989.

8. White E, et al. Apatite-An Adaptive Framework Structure. School of Materials.

9. Elliott JC. Structure and Chemistry of the Apatites and Other Calcium Orthophosphates. Elsevier: Amsterdam; 1994.

10. Birchall JD. "The importance of the study of biominerals to materials technology," In: Biomineralization: Chemical and Biochemical Perspectives, editor Mann S, Webb J, Williams RJP. New York, NY: VCH Publishers; p. 491-509, 1989.

11. Currey JD. The design of mineralised hard tissues for their mechanical functions. J Exp Biol 1999;202:3285-3294.

12. Calderyn L, Stott MJ, Rubio A. Electronic and crystallographic structure of apatite. Physical Reviews 2003; B 67:1341-1346.

13. Balogh MB, Fehrenbach MJ. Dental Embriology, Histology, and Anatomy. 2nd ed. Missouri: Evolve Elsevier; 2006. p. 192-201.

14. Mjor, A. Ole Feejerskov. Human Oral Embriology and Histology. Alih bahasa Fazwishni Siregar. Jakarta: Widya Medika.

15. Saini R. Ozone therapy in dentistry: a strategic review. J Nat Sc Biol Med 2011;2:151-153. 